\title{
A New Approach of Fuzzy-Wavelet Method's Implementation in Time Series Analysis
}

\section{S. Hansun dan Subanar}

\begin{abstract}
Recently, many soft computing methods have been used and implemented in time series analysis. One of the methods is fuzzy hybrid model which has been designed and developed to improve the accuracy of time series prediction.

Popoola has developed a fuzzy hybrid model which using wavelet transformation as a preprocessing tool, and commonly known as fuzzywavelet method. In this thesis, a new approach of fuzzy-wavelet method has been introduced. If in Popoola's fuzzy-wavelet, a fuzzy inference system is built for each decomposition data, then on the new approach only two fuzzy inference systems will be needed. By that way, the computation needed in time series analysis can be pressed.

The research is continued by making new software that can be used to analyze any given time series data based on the forecasting method applied. As a comparison there are three forecasting methods implemented on the software, i.e. fuzzy conventional method, Popoola's fuzzy-wavelet, and the new approach of fuzzy-wavelet method. The software can be used in short-term forecasting (single-step forecast) and long-term forecasting. There are some limitation to the software, i.e. maximum data can be predicted is 300, maximum interval can be built is 7 , and maximum transformation level can be used is 10 . Furthermore, the accuracy and robustness of the proposed method will be compared to the other forecasting methods, so that can give us a brief description about the accuracy and robustness of the proposed method.
\end{abstract}

Keywords- fuzzy, wavelet, time series, soft computing

\section{PENDAhULUAN}

$\mathrm{D}$ ata runtun waktu (time series) adalah suatu rangkaian pengamatan berdasarkan urutan waktu dari karakteristik kuantitatif dari satu atau kumpulan kejadian yang diambil dalam periode waktu tertentu. Data runtun waktu banyak diterapkan dalam berbagai bidang kehidupan, seperti sistem Ekonomi, Biologi, Fisika, hingga bidang Geografi dan Meteorologi.

Seng Hansun, Graduate student in Computer Science, Department of Mathematics and Natural Science, Gadjah Mada University, Yogyakarta.

Subanar, Lecturer in Computer Science, Department of Mathematics and Natural Science, Gadjah Mada University, Yogyakarta.
Untuk memahami karakteristik-karakteristik yang dimiliki oleh data runtun waktu, para peneliti telah mengadopsi metode-metode analisis data runtun waktu (time series analysis). Salah satu tujuan analisis data runtun waktu tidak lain adalah untuk menemukan suatu keteraturan atau pola yang dapat digunakan dalam peramalan kejadian mendatang, perubahan tata kota yang mengurangi debit produksi, kurangnya perawatan (maintenance) serta keterbatasan anggaran dan sarana/prasarana. Persoalan yang harus dipecahkan adalah bagaimana agar distribusi air ke tujuan berjalan secara simultan, yakni antara supply air dengan demand pelanggan ditengah minimnya anggaran biaya.

Sistem dibagi atas 3 bagian yaitu input, proses dan output, seperti yang ditunjukkan gambar 1 .

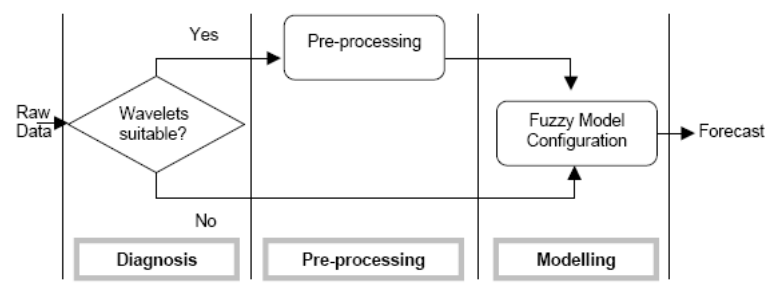

Gambar 1 Skema pra-pemrosesan dengan wavelet [1].

Dalam Tesis ini, akan dilakukan analisis peramalan data runtun waktu melalui suatu pendekatan baru metode fuzzy-wavelet. Bila dalam metode fuzzy-wavelet sebelumnya [2], [1] dibangun suatu model fuzzy untuk setiap komponen wavelet hasil dekomposisi, maka dalam metode ini hanya dua model fuzzy yang akan dibangun untuk keseluruhan data hasil dekomposisi wavelet. Selanjutnya data hasil peramalan yang diperoleh melalui transformasi wavelet tersebut akan diinversikan kembali menjadi data awal hasil peramalan. Tingkat akurasi dan kehandalan peramalan data runtun waktu melalui pendekatan baru metode fuzzywavelet ini selanjutnya akan dianalisis dan dibandingkan dengan akurasi dan kehandalan peramalan data runtun waktu dengan beberapa metode lainnya.

\section{TINJAUAN TEORI}

\subsection{Data Runtun Waktu}


Menurut [3], analisis data runtun waktu (time series) berarti memecah data lampau menjadi komponen-komponen dan memproyeksikannya ke depan (forecasting). Dengan kata lain, tujuan analisis data runtun waktu adalah mengindentifikasi komponen faktor yang dapat memengaruhi nilai dalam deret data, sehingga dapat digunakan untuk peramalan baik jangka pendek maupun jangka panjang [4].

\subsection{Fuzzy}

Pada perkembangan teori himpunan, Zadeh memperkenalkan himpunan fuzzy sebagai alat untuk merepresentasi dan memanipulasi data yang tidak bernilai 'tegas', namun agak 'samar' (fuzzy) [5]. Jika pada himpunan tegas, nilai keanggotaan hanya memiliki dua kemungkinan, yakni 0 (bukan anggota suatu himpunan) atau 1 (anggota suatu himpunan); maka pada himpunan fuzzy, nilai keanggotaan terletak pada rentang 0 sampai 1.

Definisi 2.1 : Misal $X$ adalah suatu himpunan tidak kosong. Suatu himpunan fuzzy $A$ dalam $X$ ditentukan oleh fungsi keanggotaan

$$
\mu_{A}: X \rightarrow[0,1]
$$

dimana $\mu_{A}(x)$ diartikan sebagai nilai (derajat) keanggotaan elemen $x$ dalam himpunan fuzzy $A$ untuk setiap $x \in X$.

Kusumadewi [6], mendefinisikan fungsi keanggotaan (membership function) sebagai suatu kurva yang menunjukkan pemetaan titiktitik input data ke dalam nilai (derajat) keanggotaan yang memiliki interval antara 0 sampai 1.

Secara umum, suatu sistem fuzzy adalah sistem apapun yang variabel-variabelnya (setidaknya, beberapa di antaranya) merupakan himpunan fuzzy. Sistem inferensi fuzzy atau Fuzzy Inference System (FIS) juga umum dikenal sebagai fuzzy logic control systems atau fuzzy controllers, yang mampu memanfaatkan pengetahuan (knowledge) yang diperoleh dari operator manusia (human operator) [7].

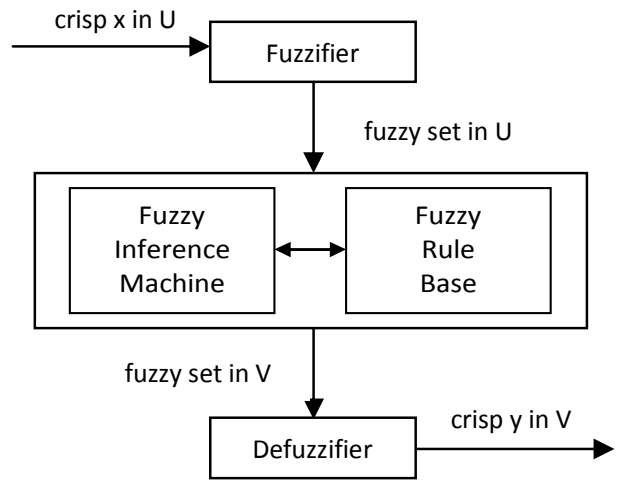

Gambar 2 Sistem inferensi fuzzy [5].

\subsection{Wavelet}

Wavelet berarti gelombang kecil, sedangkan sebagai pembanding, sinus dan kosinus adalah gelombang besar [8]. Suatu fungsi $\psi($. didefinisikan sebagai wavelet jika memenuhi dua syarat berikut:

$$
\begin{aligned}
& \text { (1). } \int_{-\infty}^{\infty} \psi(u) d u=0, \\
& \text { (2). } \int_{-\infty}^{\infty} \psi^{2}(u) d u=1
\end{aligned}
$$

Transformasi wavelet terbagi atas dua jenis, yakni Transformasi Wavelet Kontinu (Continuous Wavelet Transform/ CWT) dan Transformasi Wavelet Diskrit (Discrete Wavelet Transform/ DWT). Transformasi wavelet kontinu (CWT) didesain untuk menangani data runtun waktu yang terdefinisi dalam seluruh bilangan real, sedangkan transformasi wavelet diskrit (DWT) hanya menangani data runtun waktu yang terdefinisi pada jangkauan bilangan bulat (yakni $t=0,1, \ldots, N-1$ dimana $N$ menyatakan jumlah data dalam data runtun waktu tersebut) [8].

Transformasi dengan menggunakan DWT mensyaratkan data yang digunakan memenuhi kelipatan $2^{J}$. Namun, kebanyakan data runtun waktu dalam dunia nyata memiliki jumlah data yang tidak memenuhi kelipatan tersebut. Untuk itu modifikasi DWT, yakni MODWT yang tidak mensyaratkan hal tersebut di atas, banyak digunakan dalam analisis data runtun waktu.

Definisi 2.2 [4], Filter wavelet MODWT $\tilde{h}_{l}$ ] melalui $\tilde{h}_{2} \equiv h_{l} / \sqrt{2}$ dan filter skala MODWT $\left\langle g_{n}\right\}$ melalui $g_{2} \equiv g_{I} / \sqrt{2}$. Sehingga syarat suatu filter wavelet MODWT harus memenuhi persamaan berikut:

$$
\sum_{i=0}^{i-1} \tilde{h}_{l}=0, \sum_{i=0}^{i-1} \tilde{h}_{l}{ }^{2}=\frac{1}{2}, \sum_{i=-\infty}^{\infty} \tilde{h}_{l} \tilde{h}_{l+2 m}=0 \text {. }
$$

Demikian juga, filter skala MODWT harus memenuhi persamaan berikut:

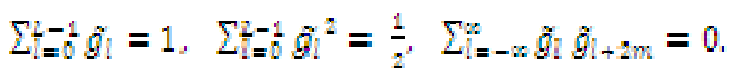

\section{Metode Penelitian}

\subsection{Fuzzy Time Series}

Pada perkembangan sistem fuzzy [9],[10], memperkenalkan suatu metode peramalan data runtun waktu yang menggunakan sistem inferensi fuzzy dengan basis yang diperkenalkan oleh Wang dan Mendel. Metode tersebut dikenal sebagai fuzzy time series. Berikut langkahlangkah penerapan fuzzy time series: 
1. Definisikan himpunan semesta $U$ dan bagi menjadi beberapa $a^{2}$ interval $u_{n}$ dengan panjang yang sama. Himpunan semesta yang digunakan adalah persentase perubahan data runtun waktu $i$ ke $i+1$.

2. Tentukan kepadatan distribusi dari persentase perubahan data runtun waktu dengan mengurutkan data tersebut ke dalam interval yang bersesuaian. Selanjutnya tentukan jumlah data yang terdapat dalam masingmasing interval.

Temukan interval yang memiliki jumlah data terbanyak dan bagi menjadi empat sub interval dengan panjang yang sama. Kemudian bagi interval yang memiliki jumlah data terbanyak kedua menjadi tiga sub interval dengan panjang yang sama. Interval yang memiliki jumlah data terbanyak ketiga dibagi menjadi dua sub interval dengan panjang yang sama. Untuk interval-interval lainnya, biarkan seperti semula.

3. Definisikan himpunan- himpunan fuzzy $A i$ berdasarkan interval yang terbentuk dan fuzzifikasi persentase perubahan data runtun waktu tersebut. Himpunan fuzzy $A \dot{i}$ menunjukkan variabel linguistik dari persentase perubahan data runtun waktu. Seperti dalam [9], digunakan fungsi keanggotaan segitiga untuk mendefinisikan himpunan-himpunan fuzzy $A \hat{i}$
4. Defuzzifikasi data fuzzy menggunakan rumus peramalan berikut (Stevenson dan Porter, 2009):

$$
\left\{\begin{array}{lr}
\frac{1.5}{\frac{1}{a_{1}}+\frac{1}{a_{n}},} & \text { if } j=1 \\
\frac{2}{0.5}+\frac{1}{a_{j-1}}+\frac{1}{a_{j-1}}, & \text { if } 2 \leq j \leq n-1 \\
\frac{1.5}{0.5}, & \text { if } j=n \\
\frac{0.1}{a_{n-1}}+\frac{1}{a_{n}} &
\end{array}\right.
$$

dimana $a_{j-1}, a_{j}, a_{j+1}$ merupakan titik-titik tengah dari interval fizzy $A_{j-1}, A_{j}, A_{j+1}$ secara benurutan. $t_{j}$ menunjukkan persentase perubahan data runtun waktu hasil peramalan. Selanjutnya, persentase hasil peramalan tersebut digunakan untuk menentukan data runtun waktu hasil peramalan.

\subsection{Metode Peramalan Fuzzy-Wavelet Popoola}

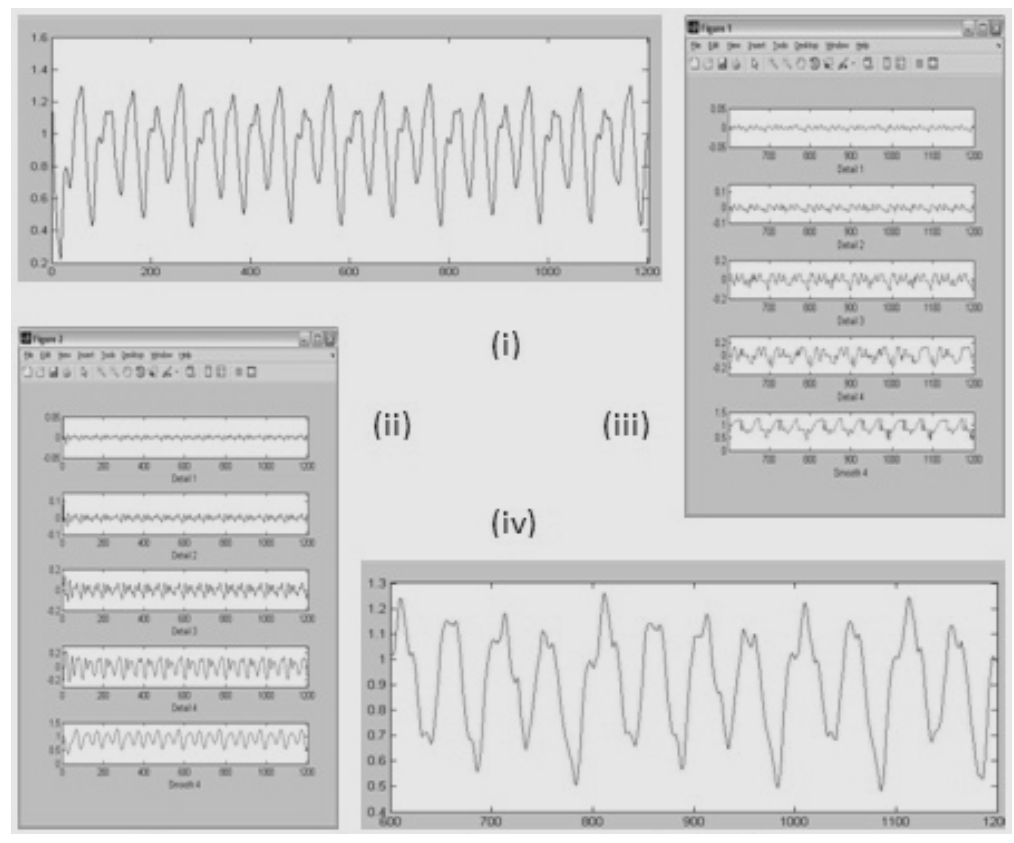

Gambar 3. Prosedur metode peramalan hybrid fuzzy-wavelet.

Generate ( i ), Transform ( ii ), Predict ( iii ), Aggregate and inverse ( iv ) 
Pada langkah pertama, data runtun waktu dibangkitkan (generate) dalam sistem. Selanjutnya, data mentah (raw series) tersebut ditransformasi (transform) dengan menggunakan transformasi wavelet MODWT pada level yang ditentukan. Setiap komponen hasil transformasi, baik bagian detail maupun smooth, kemudian diprediksi (predict) dengan membangun suatu sistem inferensi fuzzy. Hasil prediksi yang telah dilakukan selanjutnya digabung dan diinversikan kembali (aggregate and inverse) untuk memberikan hasil peramalan data runtun waktu secara keseluruhan.

\subsection{Pendekatan Baru Metode Peramalan Fuzzy- Wavelet}

Pada langkah pertama, data runtun waktu dibangkitkan (generate) dalam sistem. Selanjutnya, data mentah (raw series) tersebut ditransformasi (transform) dengan menggunakan transformasi wavelet MODWT pada level yang ditentukan. Data hasil transformasi kemudian diprediksi (predict) dengan membangun dua sistem inferensi fuzzy, satu untuk bagian smooth dan satu lagi untuk bagian detail. Hasil prediksi yang telah dilakukan selanjutnya digabung dan diinversikan kembali (aggregate and inverse) untuk memberikan hasil peramalan data runtun waktu secara keseluruhan.

\subsection{Mean Square Error (MSE)}

Kriteria MSE menyatakan besarnya kesalahan rata-rata kuadrat dari suatu metode peramalan, dengan rumus perhitungan

$$
\text { MSE }=\frac{\sum_{t=1}^{n} e_{t}^{2}}{n},
$$

dimana $n$ menyatakan jumlah data dan $\varepsilon_{z}$ adalah nilai kesalahan hasil ramalan yang diperoleh dari $X_{t}-\hat{X}_{\vec{t}}$ Dalam hal ini, $X_{t}$ adalah nilai data aktual dan $\hat{X}_{t}$ adalah nilai ramalannya.

\subsection{Mean Absolute Percentage Error (MAPE)}

Nilai MAPE memberikan petunjuk mengenai seberapa besar rata-rata kesalahan absolut peramalan dibandingkan dengan nilai sebenarnya, dan dinyatakan dengan rumus

$$
\text { MAPE }=\frac{\sum_{t=1}^{n}\left|\frac{\theta_{t}}{X_{t}}\right|}{n} \times 100,
$$

dimana $n$ adalah jumlah data dan $e_{t}$ adalah nilai kesalahan ramalan yang diperoleh dari $X_{t}-\hat{X}_{t}$ Nilai data aktual dinotasikan dengan $X_{t}$ dan $\tilde{X}_{t}$ adalah nilai ramalannya.

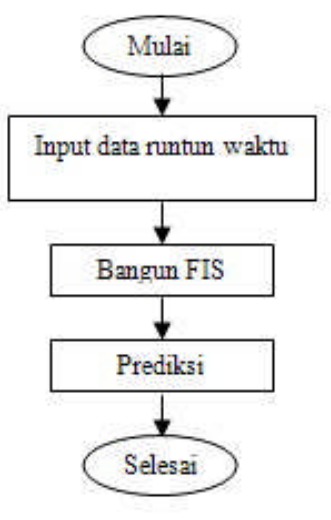

(i)

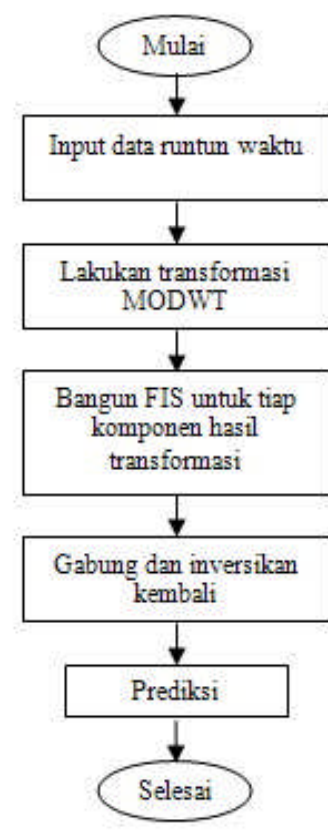

(ii)

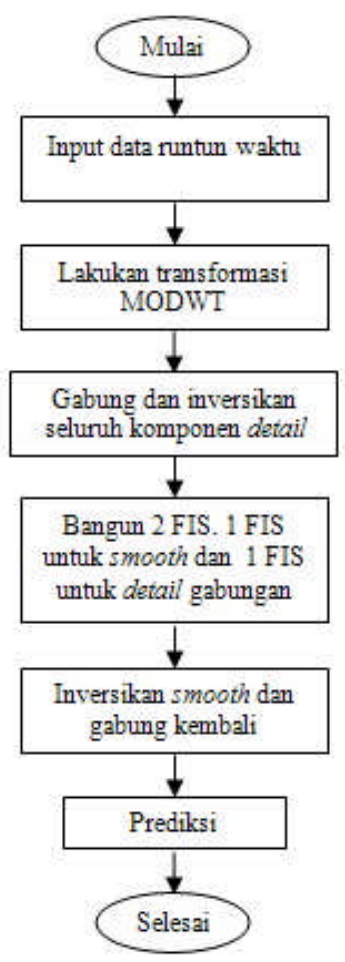

(iii)

Gambar 4 Prosedur metode peramalan fuzzy (i), fuzzy-wavelet Popoola (ii), dan pendekatan baru fuzzy-wavelet (iii) 


\section{Hasil Penelitian Dan Pembahasan}

Pendekatan baru metode fuzzy-wavelet yang dikembangkan dalam penelitian ini akan diterapkan ke dalam beberapa data runtun waktu, di antaranya Mackey-Glass chaotic time series dan beberapa kasus di dunia nyata.

Tabel 1 Data runtun waktu yang digunakan dalam analisis

\begin{tabular}{|l|l|c|}
\hline No & Data runtun waktu & Jumlah data \\
\hline 1. & Mackey-Glass chaotic & 700 \\
\hline 2. & IHSG & 698 \\
\hline 3. & ISAT & 1742 \\
\hline 4. & Plastic & 300 \\
\hline 5. & Cars & 410 \\
\hline
\end{tabular}

Tabel 2! MSE data runtun waktu yang diterapkan aengan beberapa metode peramalan

\begin{tabular}{|c|c|c|c|c|c|c|c|c|c|}
\hline \multirow{2}{*}{ Data } & \multicolumn{3}{|c|}{$\rho=1$} & \multicolumn{3}{|c|}{$\rho=3$} & \multicolumn{3}{c|}{$\rho=5$} \\
\cline { 2 - 11 } & $F$ & $F W P$ & NFW & $F$ & $F W P$ & NFW & $F$ & $F W P$ & NFW \\
\hline M-Glass & $\begin{array}{c}4,775251 \mathrm{E}- \\
03\end{array}$ & $\begin{array}{c}1,341992 \mathrm{E}- \\
03\end{array}$ & $\begin{array}{c}7,447604 \mathrm{E}- \\
02\end{array}$ & $\begin{array}{c}4,345669 \mathrm{E}- \\
03\end{array}$ & $\begin{array}{c}2,453867 \mathrm{E}- \\
03\end{array}$ & $\begin{array}{c}6,572221 \mathrm{E}- \\
02\end{array}$ & $\begin{array}{c}5,977578 \mathrm{E}- \\
03\end{array}$ & 0,1967439 & 0,0795824 \\
\hline IHSG & $\begin{array}{c}2,273183 \mathrm{E}+ \\
07\end{array}$ & $\begin{array}{c}5,909880 \mathrm{E}+ \\
08\end{array}$ & 8773645 & $\begin{array}{c}5,985730 \mathrm{E}+ \\
08\end{array}$ & $\begin{array}{c}4,881586 \mathrm{E}+ \\
08\end{array}$ & $\begin{array}{c}1,389701 \mathrm{E}+ \\
08\end{array}$ & $\begin{array}{c}3,182664 \mathrm{E}+ \\
09\end{array}$ & $\begin{array}{c}5,386850 \mathrm{E}+ \\
08\end{array}$ & $\begin{array}{c}2,330389 \mathrm{E}+ \\
08\end{array}$ \\
\hline ISAT & $\begin{array}{c}2,633701 \mathrm{E}+ \\
07\end{array}$ & $\begin{array}{c}1,085980 \mathrm{E}+ \\
11\end{array}$ & $\begin{array}{c}8,908248 \mathrm{E}+ \\
07\end{array}$ & $\begin{array}{c}6,908997 \mathrm{E}+ \\
07\end{array}$ & $\begin{array}{c}7,208332 \mathrm{E}+ \\
10\end{array}$ & $\begin{array}{c}6,078653 \mathrm{E}+ \\
08\end{array}$ & $\begin{array}{c}1,423617 \mathrm{E}+ \\
08\end{array}$ & $\begin{array}{c}2,519707 \mathrm{E}+ \\
11\end{array}$ & $\begin{array}{c}1,562906 \mathrm{E}+ \\
09\end{array}$ \\
\hline Plastic & 1994364 & 7240350 & 3032824 & 7800978 & $\begin{array}{c}2,864544 \mathrm{E}+ \\
07\end{array}$ & $\begin{array}{c}1,515512 \mathrm{E}+ \\
07\end{array}$ & $\begin{array}{c}1,440986 \mathrm{E}+ \\
07\end{array}$ & $\begin{array}{c}4,149141 \mathrm{E}+ \\
07\end{array}$ & $\begin{array}{c}3,630372 \mathrm{E}+ \\
08\end{array}$ \\
\hline Cars & $1,484754 \mathrm{E}+$ & $6,144925 \mathrm{E}+$ & 4097596 & $\begin{array}{c}2,118501 \mathrm{E}+ \\
08\end{array}$ & $\begin{array}{c}7,987798 \mathrm{E}+ \\
07\end{array}$ & $\begin{array}{c}2,396010 \mathrm{E}+ \\
07\end{array}$ & $\begin{array}{c}2,376443 \mathrm{E}+ \\
08\end{array}$ & $\begin{array}{c}8,213433 \mathrm{E}+ \\
07\end{array}$ & $\begin{array}{c}9,416629 \mathrm{E}+ \\
07\end{array}$ \\
\hline$\sum$ best & 2 & 1 & 2 & 2 & 1 & 2 & 3 & 1 & 1 \\
\hline$\sum$ worst & 1 & 3 & 1 & 2 & 2 & 1 & 2 & 2 & 1 \\
\hline$\Delta \Sigma$ & 1 & -2 & 1 & 0 & -1 & 1 & 1 & -1 & 0 \\
\hline
\end{tabular}

1. Warna merah menunjukkan kehandalan yang paling buruk, warna hijau menunjukkan kehandalan yang cukup, dan warna biru menunjukkan kehandalan 1. Warna merah menunjukkan kehandalan yang paling buruk, warna hijau menunjukkan kehandalan yang cukup,
yang terbaik.

2. $\sum$ best adalah jumlah kasus dengan kehandalan terbaik, $\sum$ worst adalah jumlah kasus dengan kehandalan terburuk.

$3 . \Delta \Sigma$ adalah gambaran tingkat kehandalan masing-masing metode peramalan yang diperoleh dari selisih $\Sigma$ best dengan $\Sigma$ worst.

4. F (Fuzzy), FWP (Fuzzy-Wavelet Popoola), NFW (New Fuzzy-Wavelet). metode fuzzy-wavelet yang diusulkan, maka akan dilakukan perbandingan antara kehandalan pendekatan baru ini dengan metode konvensional fuzzy dan hybrid fuzzy-wavelet yang dikembangkan oleh Popoola. Kehandalan pendekatan baru metode fuzzy-wavelet ini diukur dengan menggunakan kriteria MSE (Mean Square Error).

Tabel 2 memperlihatkan kehandalan masingmasing metode yang digunakan, sementara tabel 3 menunjukkan tingkat akurasinya. Pada percobaan ini digunakan beberapa batasan berikut:

1. Jumlah data runtun waktu yang dianalisis (n)

2. Jumlah interval yang digunakan

3. Level atau tingkat transformasi wavelet yang digunakan $(\mathrm{k})$

4. Lompatan peramalan yang digunakan (p) :
Untuk mengetahui kehandalan pendekatan baru 
Tabel 3 MAPE data runtun waktu yang diterapkan aengan beberapa metode peramalan

\begin{tabular}{|c|c|c|c|c|c|c|c|c|c|}
\hline \multirow{2}{*}{ Data } & \multicolumn{3}{|c|}{$p=1$} & \multicolumn{3}{|c|}{$p=3$} & \multicolumn{3}{|c|}{$p=5$} \\
\hline & $F$ & FWP & NFW & $F$ & $F W P$ & NFW & $F$ & FWP & NFW \\
\hline M-Glass & $\begin{array}{c}2,890525 \mathrm{E}- \\
02\end{array}$ & $\begin{array}{c}2,015754 \mathrm{E}- \\
02\end{array}$ & 0,1390477 & 0,0516403 & $\begin{array}{c}4,700105 \mathrm{E}- \\
02\end{array}$ & 0,1841792 & $\begin{array}{c}7,361878 \mathrm{E}- \\
02\end{array}$ & 0,4742935 & 0,2271642 \\
\hline IHSG & $\begin{array}{c}1,708466 \mathrm{E}- \\
02\end{array}$ & $\begin{array}{c}6,650856 \mathrm{E}- \\
02\end{array}$ & $\begin{array}{c}1,160473 \mathrm{E}- \\
02\end{array}$ & $\begin{array}{c}6,035809 \mathrm{E}- \\
02\end{array}$ & $\begin{array}{c}6,378856 \mathrm{E}- \\
02\end{array}$ & $\begin{array}{c}4,486998 \mathrm{E}- \\
02\end{array}$ & 0,1466782 & $\begin{array}{c}7,141779 \mathrm{E}- \\
02\end{array}$ & $\begin{array}{c}6,038423 \mathrm{E}- \\
02\end{array}$ \\
\hline ISAT & $\begin{array}{c}7,503751 \mathrm{E}- \\
03 \\
\end{array}$ & 0,4626243 & $\begin{array}{c}1,000185 \mathrm{E}- \\
02\end{array}$ & $\begin{array}{c}1,242561 \mathrm{E}- \\
02\end{array}$ & 0,3540287 & $\begin{array}{c}2,156282 \mathrm{E}- \\
02\end{array}$ & $\begin{array}{c}1,733067 \mathrm{E}- \\
02\end{array}$ & 0,5609612 & $\begin{array}{c}3,220621 \mathrm{E}- \\
02 \\
\end{array}$ \\
\hline Plastic & $\begin{array}{c}3,183597 \mathrm{E}- \\
02\end{array}$ & $\begin{array}{c}7,564281 \mathrm{E}- \\
02\end{array}$ & $\begin{array}{c}3,986766 \mathrm{E}- \\
02\end{array}$ & $\begin{array}{c}6,508838 \mathrm{E}- \\
02\end{array}$ & 0,1225441 & $\begin{array}{c}9,195928 \mathrm{E}- \\
02 \\
\end{array}$ & $\begin{array}{c}8,919209 \mathrm{E}- \\
02\end{array}$ & 0,1301286 & 0,427019 \\
\hline Cars & 0,3576258 & 0,2431357 & $\begin{array}{c}6,735342 \mathrm{E}- \\
02 \\
\end{array}$ & 0,5305875 & 0,2916766 & 0,1669627 & 0,5882376 & 0,3124987 & 0,2671533 \\
\hline$\sum$ best & 2 & 1 & 2 & 2 & 1 & 2 & 3 & 0 & 2 \\
\hline$\sum$ worst & 1 & 3 & 1 & 1 & 3 & 1 & 2 & 2 & 1 \\
\hline$\Delta \Sigma$ & 1 & -2 & 1 & 1 & -2 & 1 & 1 & -2 & 1 \\
\hline
\end{tabular}

Catatan:

1. Warna merah menunjukkan tingkat akurasi yang paling buruk, warna hijau menunjukkan tingkat akurasi yang cukup, dan warna biru menunjukkan tingkat akurasi yang terbaik.

2. $\Sigma$ best adalah jumlah kasus dengan tingkat akurasi terbaik, $\Sigma$ worst adalah jumlah kasus dengan tingkat akurasi terburuk. 3. $\Delta \Sigma$ adalah gambaran tingkat akurasi masing-masing metode peramalan yang diperoleh dari selisih $\Sigma$ best dengan $\Sigma$ worst.

4. F (Fuzzy), FWP (Fuzzy-Wavelet Popoola), NFW (New Fuzzy-Wavelet).

\section{KESIMPULAN DAN SARAN}

\subsection{Kesimpulan}

Berdasarkan hasil kajian teoritis sehubungan dengan dasar-dasar teori wavelet dan fuzzy, pengembangan pendekatan baru metode fuzzywavelet dalam analisis data runtun waktu, serta kajian empiris penerapan pendekatan baru metode fuzzy-wavelet pada beberapa data runtun waktu di dunia nyata, dapat ditarik beberapa kesimpulan sebagai berikut:

1. Komputasi metode hybrid fuzzy-wavelet Popoola sangat tergantung pada tingkat atau level transformasi wavelet yang digunakan. Semakin tinggi level transformasi yang digunakan, semakin banyak sistem inferensi fuzzy yang harus dibangun.

2. Pendekatan baru metode fuzzy-wavelet hanya memodelkan 2 (dua) sistem inferensi fuzzy tanpa tergantung pada level transformasi yang digunakan dalam analisis data runtun waktu.

3. Pendekatan baru metode fuzzy-wavelet terbukti memiliki kehandalan dan tingkat akurasi yang baik dan dapat digunakan untuk peramalan jangka pendek maupun peramalan jangka panjang.

4. Metode konvensional fuzzy memiliki kehandalan dan tingkat akurasi yang lebih baik dibandingkan dengan metode hybrid fuzzy-wavelet Popoola, dan dapat digunakan untuk peramalan baik jangka pendek maupun jangka panjang.
5. Kehandalan dan tingkat akurasi metode hybrid fuzzy-wavelet Popoola sangat tergantung pada level transformasi yang digunakan dan komponen (detail dan smooth) yang diikutsertakan dalam proses peramalan.

6. Secara umum, semakin besar lompatan peramalan (p) yang dilakukan, semakin besar error yang terjadi.

\subsection{Saran}

Melalui hasil kajian dan penelitian yang telah dilakukan, beberapa saran yang dapat diberikan untuk pengembangan penelitian lebih lanjut adalah sebagai berikut:

1. Mengembangkan prosedur penentuan tingkat atau level transformasi wavelet yang diperlukan, sehingga dapat memberikan hasil peramalan data runtun waktu yang lebih baik.

2. Membandingkan kehandalan dan tingkat akurasi metode hybrid fuzzy-wavelet dengan metode hybrid lainnya yang menggunakan wavelet sebagai alat pra-pemrosesan (contoh wavelet neural networks).

3. Melakukan analisis penerapan pendekatan baru metode fuzzy-wavelet terhadap data runtun waktu yang bersifat nonlinear. 


\section{DAFTAR PUSTAKA}

[1] Popoola, A.O., 2007, Fuzzy-Wavelet Method for Time Series Analysis, Disertasi, Department of Computing, School of Electronics and Physical Sciences, University of Surrey, Surrey.

[2] Popoola, A., Ahmad, S. dan Ahmad, K., 2004, A FuzzyWavelet Method for Analyzing Non-Stationary Time Series, Proc. of the $5^{\text {th }}$ International Conference on Recent Advances in Soft Computing RASC2004, Nottingham, United Kingdom, 231-236.

[3] Render, B., Stair Jr., R.M. dan Hanna, M.E., 2003 , Quantitative Analysis for Management, $8^{\text {th }}$ edition, Pearson Education, Inc., New Jersey.

[4] Subanar dan Suhartono, 2009, Wavelet Neural Networks untuk Peramalan Data Time Series Finansial, Program Penelitian Ilmu Dasar Perguruan Tinggi, FMIPA UGM, Yogyakarta.

[5] Fuller, R., 1995, Neural Fuzzy Systems, Abo, Finland.
[6] Kusumadewi, S. dan Purnomo, H., 2004, Aplikasi Logika Fuzzy untuk Pendukung Keputusan, Graha Ilmu, Yogyakarta.

[7] Klir, G.J. dan Yuan, B., 1995, Fuzzy Sets and Fuzzy Logic: Theory and Applications, Prentice-Hall, Inc., United States of America.

[8] Percival, D.B. dan Walden, A.T., 2000, Wavelet Methods for Time Series Analysis, Cambridge University Press, New York.

[9] Chen, S.-M. dan Hsu, C.-C., 2004, A New Method to Forecast Enrollments Using Fuzzy Time Series, International Journal of Applied Science and Engineering, 2, 3, 234-244.

[10] Stevenson, M. dan Porter, J.E., 2009, Fuzzy Time Series Forecasting Using Percentage Change as the Universe of Discourse, World Academy of Science, Engineering and $\begin{array}{lrr}\text { Technology, } & 27, & 55,\end{array}$ http://www.waset.org/journals/waset/v55/. 